\title{
The role of selenium in inherited breast cancer in women
}

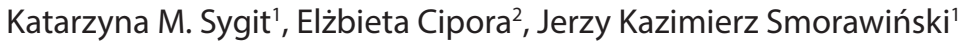 \\ ${ }^{1}$ Calisia University, Kalisz, Poland \\ 2Jan Grodek State Vocational Academy in Sanok, Poland
}

\begin{abstract}
High incidence of "diseases of affluence" (particularly cancer) motivates numerous research teams to look for causes of morbidity, as well as to search for preventive methods and effective therapeutic measures. The aim of this paper is to present literature on effects of selenium on development of inherited breast cancer in women. The results of national and international research show importance of selenium in prevention and treatment of cancerous diseases, including inherited cancer; they also show the risk of developing cancer in people with hereditary risks and low selenium level. It should be emphasized that the intake of selenium in amounts necessary for proper functioning - given numerous deficiencies (first in the soil, then in food products coming from selenium-deficient soil) - is the first and most important step in prevention and treatment of cancer.
\end{abstract}

KEY WORDS: cancer, prevention, selenium, inherited cancer.

ADDRESS FOR CORRESPONDENCE: Katarzyna M. Sygit, Calisia University, 4 Nowy Świat St., 62-800 Kalisz, Poland, e-mail:k.sygit@akademiakaliska.edu.pl

\section{INTRODUCTION}

Selenium is one of the microelements necessary for the proper development and growth of the human body [1-3]. For a long time, however, this element was considered to be toxic. In areas with a high concentration of selenium in soil, lethal cattle poisoning occurred, while people experienced hair loss or skin problems [4]. It was only in the middle of the last century that scientists proved a positive effect of selenium on the human and animal body [1-3, 5-7].

In recent decades, it has been proven in numerous studies that selenium, among other benefits: protects against the harmful effects of free radicals, as it is a component of antioxidant enzymes, e.g. glutathione peroxidase; inhibits the development of cancer cells; is necessary for the proper development of the fetus; and supports the thyroid gland, which contains the most selenium of all body organs. Selenium is involved in the synthesis of hormones produced by the thyroid and neutralizes carcinogenic elements, such as cadmium, lead, mercury, and arsenic $[8,9]$.
In the human body, selenium works through proteins in which it is embedded in the form of selenocysteine. As a component of selenoproteins, selenium plays a significant structural and enzymatic role. It stimulates the immune system in order to increase antibody production, which leads to increased activity of immune cells. Numerous studies have shown that selenium might have an impact on the risk of cancer as it is an antioxidant and therefore protects the body from the harmful effects of free radicals, increases the activity of immune cells, and inhibits the development of cancer blood vessels. The protective role of this element against pro-oxidants results from, among other things, the presence of selenium in the active center of antioxidant enzymes. One such enzyme is glutathione peroxidase (GPX), whose function is to protect cellular components (DNA, lipids) from the damaging effects of $\mathrm{H}_{2} \mathrm{O}_{2}$ and various organic peroxides produced during changes in the body [10-13].

This study presents the principal research achievements regarding the effects of selenium on the development of inherited cancers in humans. 


\section{REVIEW METHODS}

This paper includes studies in Polish and English, published from 1996 to 2018 and selected on the basis of a review of the following databases: PubMed, Web of Science, ResearchGate, and Google Scholar. The databases were searched using the following keywords and their combinations: selenium, cancer, breast cancer, inherited cancer, treatment and prevention of cancer, and analysis of literature on the subject matter. Searches were carried out using mainly electronic databases. Of 123 publications identified, those whose results were deemed to correspond most closely to the topic of this work were selected.

\section{REVIEW RESULTS \\ SELENIUM VERSUS INHERITED CANCER}

Breast cancer and ovarian cancer are the second and fifth leading causes of death from cancer (respectively) in the United States. Women with breast cancer have a $20-30 \%$ chance of having at least one relative with this condition. However, only $5-10 \%$ of cases constitute a direct result of genetic mutations in high-penetration genes, such as BRCA1 and BRCA2, as well as in TP53 and PTEN genes. Genetic tests for detecting these mutations have been clinically available since 1996 . Over 1,000 mutations have been identified in BRCA1 and BRCA2 genes (over 700 different mutations in $B R C A 1$ and 300 in BRCA2). The position of mutation in a gene affects the risk of developing both breast cancer and ovarian cancer. The cancer risk associated with penetration in $B R C A 1$ and BRCA2 mutations is subject to intensive genetic testing. "Gene penetrance" means the incidence of a feature conditioned by a given gene in the phenotype of an individual having this gene. Penetrance is expressed as a proportion of the number of individuals having a feature conditioned by a given gene to the total number of individuals having that gene. Gene penetrance may be "complete" when a gene is manifested phenotypically in all individuals with this gene variant, or "incomplete" when the gene is either manifested or not - due to environmental reasons. Table 1 presents (in \%) the risk of cancer associated with mutations of BRCA1 and BRCA2 genes, depending on the location of cancer (female breast, ovary, prostate, pancreas) $[8,9,14,15]$.

Carriers of BRCA1-related breast cancer have cancers that are biologically distinct from cancers found in carriers of $B R C A 2$ gene mutations, or sporadic breast cancers. BRCA1-related cancers typically develop in younger women and have a more aggressive nature, are of low histological grade, high proliferation rate, aneuploidy, lack of estrogen (ER) and progesterone (PR) receptors, and lack of epidermal growth factor receptor 2 (EGFR2). BRCA1-related breast cancers have a "triple negative phenotype" $[9,13]$.

The research focuses on specific BRCA gene mutations as well as gene-gene and gene-environment interactions as potential modifiers of the effects of these mutations. Mutations in susceptibility of BRCA1 and $B R C A 2$ genes are associated with a significant risk of breast cancer. Breast cancer triggered by a mutation in $B R C A 1$ and BRCA2 genes accounts for about 5-10\% of all cancers. These mutations lead to a relative risk of breast cancer 10 to 30 times higher than in the general female population and lead to almost $85 \%$ certainty that breast cancer will develop over the course of a woman's life (Table 1). In Ashkenazi Jewish women the incidence of BRCA1 mutation is 1 in 40 women [16].

The risk of breast cancer is determined by a studied population. Higher risk is indicated in studies on families, while a slightly lower risk is estimated in population studies. Furthermore, the risk of ovarian cancer is not identical for all mutations. Mutations accumulated in the central ovarian cluster region have a higher lifetime risk of cancer development [17]. Breast cancer may develop as a result of a combination of genetic and environmental factors.

Other factors, such as: birth control, number of deliveries, use of oral contraceptives, age at the time of first pregnancy; physical activity, show an impact on the risk of gene penetration in the population [16].

Most cases of inherited breast and ovarian cancer syndrome is caused by mutations in BRCA1 and BRCA2 genes (Table 2). These mutations are rare: in most populations they occur in 1:400 women, but are much more common in Ashkenazi Jewish women. In that population 1:210 women are carriers of one of three main mutations causing this syndrome (two mutations of $B R C A 1$ gene and one of BRCA2 gene) [19].

Factors suggesting $B R C A 1$ or $B R C A 2$ gene mutations are:

1. In non-Ashkenazi Jewish women:

- Two first-degree relatives (i.e. relatives on the same side of the family), with breast cancer, one diagnosed before the age of 50 .

- Three or more first- or second-degree relatives with breast cancer.

- Breast and ovarian cancer among first- and second-degree relatives.

- First-degree relative with bilateral breast cancer.

- Breast cancer in a male relative.

- Two or more first- or second-degree relatives with ovarian cancer.

TABLE 1. Data referring to the risk of cancer associated with mutations of BRCA1 and BRCA2 genes, depending on the location of cancer

\begin{tabular}{|l|c|c|}
\hline Cancer location & $\begin{array}{c}\text { BRCA1 } \\
\text { mutation (\%) }\end{array}$ & $\begin{array}{c}\text { BRCA2 } \\
\text { mutation (\%) }\end{array}$ \\
\hline Female breast & $50-80$ & $40-70$ \\
\hline Ovary & $<40$ & $<20$ \\
\hline Prostate & $<30$ & $<39$ \\
\hline Pancreas & $1.3-3.2$ & $2.3-7$ \\
\hline
\end{tabular}

Source: [22] 
TABLE 2. Genes whose mutations cause inherited breast and ovarian cancer syndrome

\begin{tabular}{|l|c|}
\hline $\begin{array}{l}\text { Type of mutated } \\
\text { gene }\end{array}$ & $\begin{array}{c}\text { An approximate percentage } \\
\text { of the development } \\
\text { of a genetically determined } \\
\text { breast-ovarian cancer } \\
\text { syndrome in carriers }\end{array}$ \\
\hline BRCA1 & $\sim 48$ \\
\hline BRCA2 & $\sim 27$ \\
\hline $\begin{array}{l}\text { CHEK2, ATM, BPIP1, } \\
\text { PALB2 and other genes }\end{array}$ & $\sim 25$ \\
\hline
\end{tabular}

Source: [22]

2. In Ashkenazi Jewish women:

- First-degree relative with breast or ovarian cancer.

- Two second-degree relatives with breast or ovarian cancer $[18,19]$.

The degree of relationship is a method of assessing the connection between people from a common ancestor, i.e. relatives. Determining the degree of relationship has social and legal significance. Relationship is calculated by means of lines and degrees. First-degree relatives are parents, children, and siblings. Grandmothers/grandparents are classified as second-degree relatives [18].

Cancerous transformation may occur as a result of mutations arising within:

- proto-oncogenes,

- suppressor genes,

- apoptosis-controlling genes,

- genes controlling the repair of damaged DNA [15]

Genes whose mutations may increase the risk of breast cancer, are not only $B R C A 1$ and $B R C A 2$, but also: ATM, p53, RAS [20].

Table 2 presents genes whose mutations cause hereditary breast and ovarian cancer syndrome. The table lists an approximate percentage of the development of hereditary breast-ovarian cancer syndrome in carriers. It depends on the type of mutated gene. Four genes have been identified that, if mutated, cause an increased but moderate risk of breast cancer:

- $C H E K 2$,

- ATM,

- $B P I P 1$,

- PALB2 [22].

In mutation carriers, each of these genes causes about 2 to 3 times higher relative risk of breast cancer [20]. Together, these genes are estimated to cause $2.3 \%$ of inherited breast cancer. In contrast, mutations in $B R C A 1$ and BRCA2 genes are thought to cause half of all dominant inherited hereditary breast cancers.

The described strategy for treating women with increased familial risk of breast and ovarian cancers includes:
- genetic analysis,

- chemoprevention,

- screening, radiology tests (mammography),

- clinical evaluation and genetic counselling [14].

The above tests may be supplemented with ultrasound and computed tomography (CT), magnetic resonance imaging (MRI) or positive emission tomography (PET) examinations of breasts.

Apart from clinical evaluation and genetic counselling, genetic testing should be carried out. Blood samples allow to assess the presence of BRCA1 and BRCA2, TP53, $P T E N$ and $A T M$ genes. Tumour examination allows the identification of growth factor receptor genes, particularly the human epidermal growth factor receptor (HER-2) $[14,18,19]$.

Chemoprevention means the use of natural or synthetic substances to inhibit, reverse or delay carcinogenesis. Chemoprevention interferes with the early stages of the cancer process, primarily inhibiting initiation and promotion [21-23].

In terms of diet and lifestyle, women with increased risk of breast cancer can be recommended:

- reduction of fat in the diet,

- avoiding obesity,

- reduction of alcohol and cigarette consumption,

- regular physical exercise [24-27].

The Egyptians used garlic as a medicine as early as in $1550 \mathrm{BC}$ to prevent many diseases, including cancer. Historically speaking, this is probably one of the oldest examples of chemoprevention.

One of the recently recommended chemoprevention methods for women with high risk of breast cancer is antiestrogen called Raloxifen (Ral), which is an effective chemopreventive factor, in combination with Omega-3 fatty acids (n-3FA ). This combination is a viable strategy that may be recommended in the future in chemoprevention tests for women with high risk of breast cancer. Raloxifene (brand name: Raloxifene by Evista) is a selective estrogen receptor modulator (SERM). The drug acts antagonistically at receptors located in bone tissue, thus reducing its resorption, increasing bone density and reducing the frequency of bone fractures. Raloxifene is an estrogen receptor antagonist in the uterus and breasts. Four-year treatment with Raloxifene significantly reduced the risk of estrogen-dependent breast cancer in postmenopausal women, compared to placebo $[19,20]$.

Another example of chemoprevention is a diet rich in tomato-based nutritional products that contain a high amount of carotenoids and lycopene, which may reduce the risk of advanced prostate cancer $[28,29]$.

Chemoprotection is a commonly used approach. Tamoxifen is used in women carrying BRCA1 or BRCA2 gene mutations. Tamoxifen (tamoxifenum by Sandoz) is a non-steroidal drug with anti-estrogenic effects; it competitively inhibits the binding of estrogens to cellu- 
lar receptors in the cytoplasm, which results in limited cell division in estrogen-dependent tissues. Women with breast cancer with positive estrogen receptors or cancers with unknown receptor status who received supplementary tamoxifen therapy had significantly fewer relapses and a higher survival rate of 10 years [18].

It should be emphasized, however, that the use of tamoxifen in women with BRCA1 and BRCA2 mutations is not well established and the most favorable duration of its administration is not known. A review of the main results of currently published studies confirms a $38 \%$ reduction in the incidence of breast cancer in women receiving tamoxifen, but its use should be narrowed to women with high risk of breast cancer and low risk of potential side effects. The role of bilateral, risk-reducing, breast removal (mastectomy) or preventive mastectomy is controversial in many ways. These controversies include the psychological significance of breast in the Western culture and the widely accepted conservative approach to surgical treatment of breast cancer. Surgical procedures should be aimed at removing breast tissue from women at risk. However, there is some relationship between reducing the risk of cancer and the cosmetic outcome of the treatment. Bilateral prophylactic oophorectomy reduces the risk of breast cancer even in women who have previously had hormone replacement therapy. There are no published randomized controlled clinical trials on the effectiveness of mammographic screening in women under the age of 50 who had a family history of breast cancer. However, published results suggest that mammography screening among women under 50 years of age who have a family history of breast cancer may detect cancer at a rate that is equivalent to that seen in women ten years older with a normal risk of breast cancer. Other preliminary studies support the use of magnetic resonance imaging (MTI) in high-risk women as it is more sensitive than mammography. Clinical examination and self-examination of the mammary glands are often recommended, but their effectiveness has not been proven. Based on numerous studies, it can be concluded that a clinical examination and mammographic screening in high-risk women under 50 may detect breast cancer with a frequency - as mentioned above - corresponding to the frequency observed in women 10 years older with regular risk $[14,18-20,30,31]$.

Studies carried out at the International Hereditary Cancer Centre of the Pomeranian Medical University in Szczecin, Poland have shown that carriers of the BRCA1 mutation display increased susceptibility to mutagens measured by the bleomycin test. This susceptibility may be normalized with some selenium formulations [4].

In Canada, there are National Hereditary Cancer Task Force' recommendations addressed to doctors who work on clinical treatment for patients with high risk of hereditary breast and ovarian cancer (HBOC) and related cancers. These recommendations are based on current practices in clinics that work with high-risk cancer patients who have mutations in BRCA1 and BRCA2 genes.

The above-mentioned recommendations apply to:

1. Supervision, including self-examination of breasts by the patient;

2. Clinical breast examination;

3. Monitoring breasts by MRI methods;

4. Observing the patient in terms of ovarian cancer;

5. Supervision over male patients.

6. Reducing the risk of cancer by using strategies that include:

- preventive removal of mammary glands (mastectomie),

- preventive removal of ovaries and fallopian tubes (salpingoophorectomia),

- pharmacological prevention,

- administration of exogenous hormones [5, 18, 31].

The main product of DNA oxidation is the oxidized deoxyguanosine derivative, 8-oxo-dG. The concentration of 8-oxo-dG in the cell reflects the level of oxidative stress. 8-oxo-dG is induced by factors that damage cell DNA. 8-oxoGua and 8-oxodG are molecular markers of cancer. They are markers of oxidative DNA damage. The above-mentioned markers may be useful in cancer diagnosis [32]. The anti-cancer properties of selenium are associated with protection against oxidative stress. In the subpopulation of female carriers of the BRCA1 mutation with no evidence of breast cancer who have undergone adnexectomy and who were previously supplemented with selenium, the 8-oxo-dG level in their DNA significantly decreased compared to the subgroup of women without supplementation $[2,5,11,33-35]$. 8 -oxo-dG is primarily repaired by a protein called BER (base excision repair). In carriers of mutations who received selenium, there was a simultaneous 8-oxo-dG reduction in cells and increase in urinary excretion of 8-oxo-dG and 8-oxo-Guo. Based on the results of the above-mentioned

TABLE 3. Incidence and mortality rate of 7 most common malignant tumors in European women in 2018

\begin{tabular}{|l|c|c|}
\hline $\begin{array}{l}\text { Type of malignant } \\
\text { tumour }\end{array}$ & $\begin{array}{c}\text { Incidence } \\
(\%)\end{array}$ & $\begin{array}{c}\text { Mortality rate } \\
(\%)\end{array}$ \\
\hline Breast cancer & 28.2 & 16.2 \\
\hline Colorectal cancer & 12.3 & 13.2 \\
\hline Lung cancer & 8.5 & 14.2 \\
\hline Uterine cancer & 6.6 & - \\
\hline Melanoma & 3.9 & - \\
\hline Pancreatic cancer & - & 7.4 \\
\hline Ovarian cancer & - & 5.2 \\
\hline $\begin{array}{l}\text { Other } \\
\text { and unspecified }\end{array}$ & 40.4 & 43.8 \\
\hline
\end{tabular}


TABLE 4. Number of new diagnoses and number of deaths in women caused by breast cancer in Europe in 2018

\begin{tabular}{|l|c|c|c|c|}
\hline \multirow{2}{*}{$\begin{array}{l}\text { Type of malignant } \\
\text { tumour }\end{array}$} & \multicolumn{2}{|c|}{ Number of new diagnoses } & \multicolumn{2}{c|}{ Number of deaths } \\
\cline { 2 - 5 } & In thousands & $\%$ & In thousands & $\%$ \\
\hline Breast cancer & 522.5 & 28.2 & 137.7 & 16.2 \\
\hline
\end{tabular}

Source: [42]

study, it may be concluded that it is very likely that selenium supplementation leads to an increase in BER enzymatic activity, which in turn leads to a reduction in the oxidative damage to the cell's DNA. To sum up, the results of the study suggest that the BRCA1 gene defect contributes to the accumulation of 8 -oxo-dG in a cell's DNA, which in turn may be responsible for the development of breast cancer in women with a mutation of this gene. Additionally, the risk of developing breast cancer in female carriers of a BRCA1 mutation may be reduced in women who have undergone adnexectomy (whose surgery was preceded by selenium supplementation) $[1,7,36-42]$.

\section{SUMMARY}

The incidence and mortality rate of malignant tumors in European women is very high (Table 3). Therefore, effective methods of preventing and treating cancer should be sought.

Particular attention should be paid to the increasing number of new diagnoses and deaths of women due to breast cancer (Table 4).

Recent studies on the effects of selenium on inherited cancers have made significant progress, mainly due to the fact that the optimal level of selenium correlates with a reduction in mortality caused by cancer. It has been proven that too low or too high a concentration of selenium in the body is harmful, whereas the optimal level of selenium varies and depends on the population. Presumably, this may be related to environmental pollution through various chemical compounds that are neutralized by selenium. Importantly, the role of selenium for human health (especially those at risk of cancer) will be greater if the optimal concentration of selenium for each person is individualized through genotype testing. There is evidence that optimizing selenium concentrations may improve the treatment results of inherited cancer.

\section{CONCLUSIONS}

1. There is a strong correlation between selenium concentration and the risk of inherited cancers.

2. There is a need to indicate the optimal selenium concentration for each person through genotype testing.

3. Selenium (Se formulations) seems to be particularly important, as well as a varied diet.

4. Selenium concentration in blood serum is a high-risk marker for inherited cancers.
5. Further observation is recommended in order to introduce selenium as a standard practice to reduce the risk of inherited cancers.

\section{DISCLOSURE}

The authors report no conflict of interest.

\section{References}

1. Duntas LH, Benvenga S. Selenium: An element for life. Endocrine 2015; 48 (3): 756-775.

2. Rayman MP. Selenium and human health. Lancet 2012; 379: 1256-1268.

3. Pfister C, Dawczynski H, Schingale FJ. Sodium selenite and cancer related lymphedema: Biological and pharmacological effects. J Trace Elem Med Biol 2016; 37: 111-116.

4. Żbikowska H. Selen w organizmach żywych. I. Toksyczność selenu i działanie antynowotworowe. Acta Universitatis Lodziensis. Folia Biochim Biophys 1997; 12: 29-37.

5. Björnstedt M, Fernandes AP. Selenium in the prevention of human cancers. EPMA J 2010; 1: 389-395.

6. Kasseroller R. Sodium selenite as prophylaxis against erysipelas in secondary lymphedema. Anticancer Res 1998; 18 (3C): 2227-2230.

7. Rayman MP. The importance of selenium to human health. Lancet 2000; 356 (9225): 233-241.

8. Ip C, Hayes C, Budnick M, Ganther HE. Chemical form of selenium critical metabolites, and cancer prevention. Cancer Res 1991; 51: 595-600.

9. Schrauzer GN. Selenium and cancer: A review. Bioinorg Chem 1976; 5: 275-281.

10. Choi MC, Bae JS, Jung SG, et al. Prevalence of germline BRCA mutations among women with carcinoma of the peritoneum or fallopian tube. J Gynecol Oncol 2018; 29 (4): e43.

11. Corso G, Feroce I, Intra M. et al. BRCA1/2 germline missense mutations: a systematic review. Eur J Cancer Prev 2018; 27 (3): 279-286.

12. Easton DF, Pharoah PD, Antoniou AC. Et al. Gene-panel sequencing and the prediction of breast-cancer risk. N Engl J Med 2015; 372 (23): 2243-2257.

13. Ghiorzo, P. Genetic predisposition to pancreatic cancer. World J Gastroenterol 2014; 20 (31): 10778-10789.

14. Edlich R, Winters KL, Lin KY. Breast cancer and ovarian cancer genetics. J Long Term Eff Med Implants 2005; 15: 533-545.

15. Patrick L. Selenium biochemistry and cancer: A review of the literature. Altern Med Rev 2004; 9 (3): 239-258.

16. Kurian AW. BRCA1 and BRCA2 mutations across race and ethnicity: distribution and clinical implications. Curr Opin Obstet Gynecol 2010; 22: 72-78. 
17. Miller AB. Screening for breast cancer in the Eastern Mediterranean Region. East Mediterr Health J 2010; 16 (10): 1022 1024.

18. Rottenberg S, Jaspers JE, Kersbergen A, et al. High sensitivity of BRCA1-deficient mammary tumors to the PARP inhibitor AZD2281 alone and in combination with platinum drugs. Proc Natl Acad Sci USA 2008; 105 (44): 17079-17084.

19. Sakai W, Swisher EM, Karlan BY, et al. Secondary mutations as a mechanism of cisplatin resistance in BRCA2-mutated cancers. Nature 2008; 451 (7182): 1116-1120.

20. Nilsonne G, Sun X, Nyström C, et al. Selenite induces apoptosis in sarcomatoid malignant mesothelioma cells through oxidative stress. Free Radic Biol Med 2006; 41 (6): 874-885.

21. Kieliszek M, Błażejak S, Gientka I. Accumulation and metabolism of selenium by yeast cells. Appl Microbiol Biotechnol 2015; 99 (13): 5373-5382.

22. Shannon KM, Chittenden A. Genetic testing in breast cancer. In: De Vita VT, Lawrence TS, Rosenberg SA. Cancer principles and practice of oncology. $10^{\text {th }}$ ed. Wolters Kluwer, Philadelphia 2015: 1157-1166.

23. Morrow M, Bernstein J, Harris R. Malignant tumors of the breast. In: De Vita VT, Lawrence TS, Rosenberg SA. Cancer principles and practice of oncology. $10^{\text {th }}$ ed. Wolters Kluwer, Philadelphia 2015: 1117-1156.

24. Vinayak S, Gilmore HL, Harris LN. In: Biology of breast cancer. De Vita VT, Lawrence TS, Rosenberg SA. Cancer principles and practice of oncology. $10^{\text {th }} \mathrm{ed}$. Wolters Kluwer, Philadelphia 2015: 1107-1116.

25. Lu J, Zhang J, Jiang C. et al. Cancer chemoprevention research with selenium in the post-SELECT era: Promises and challenges. Nutr Cancer 2016; 68 (1): 1-17.

26. Fernandes AP, Gandin V. Selenium compounds as therapeutic agents in cancer. Biochim Biophys Acta 2015; 1850 (8): 16421660.

27. Weekley CM, Harris HH. Which form is that? The importance of selenium speciation in the prevention and treatment of disease. Chem Soc Rev 2013; 42 (23): 8870-8894.

28. Combs GF. Jr. Selenium in global food systems. Br J Nutr 2001; 85 (5): 517-547.

29. Kieliszek M, Błażejak S. Selenium significance and outlook for supplementation. Nutrition 2013; 29 (5): 713-718.

30. Clark LC, Combs GF Jr, Turnbull BW, et al. Effects of selenium supplementation for cancer prevention in patients with carcinoma of the skin. A randomized controlled trial. J Am Med Assoc USA 1996; 276 (24): 1957-1963.

31. Swisher EM, Sakai W, Karlan BY, et al. Secondary BRCA1 mutations in BRCA1-mutated ovarian carcinomas with platinum resistance. Cancer Res 2008; 68 (8): 2581-2586.

32. Lipinski B. Prostate cancer vaccines, fibrin and selenium: A conceptual review. Open Prost Cancer J 2010; 3: 69-73.

33. Trainer AH, Lewis CR, Tucker K, et al. The role of BRCA mutation testing in determining breast cancer therapy. Nat Rev Clin Oncol 2010; 7 (12): 708-717.

34. Selvaraj V, Tomblin J, Armistead MY, et al. Selenium (sodium selenite) causes cytotoxicity and apoptotic mediated cell death in PLHC-1 fish cell line through DNA and mitochondrial membrane potential damage. Ecotoxicol Environ Saf 2013; 87: 80-88.

35. Byrski T, Gronwald J, Huzarski T, et al. Response to neo-adjuvant chemotherapy in women with BRCA1-positive breast cancers. Breast Cancer Res Treat 2008; 108 (2): 289-296.

36. Lener MR, Gupta S, Scott RJ, et al. Can selenium levels act as a marker of colorectal cancer risk? BMC Cancer 2013; 13: 214220 .

37. Reid ME, Duffield-Lillico AJ, Sunga A, et al. Selenium supplementation and colorectal adenomas: an analysis of te nutritional prevention of cancer trial. Int J Cancer 2006; 118 (7): 17771781.

38. Lippman SM, Klein EA, Goodman PJ, et al. Effect of selenium and vitamin $\mathrm{E}$ on risk of prostate cancer and other cancers: the Selenium and Vitamin E Cancer Prevention Trial (SELECT). JAMA 2009; 301 (1): 39-51.

39. Chen S, Parmigiani G. Meta-analysis of BRCA1 and BRCA2 penetrance. J Clin Oncol 2007; 25(11): 1329-1333.

40. Kieliszek M, Błażejak S. Current knowledge on the importance of selenium in food for living organisms: A review. Molecules 2016; 21 (5): 609-613.

41. Kieliszek M, Błażejak S, Bzducha-Wrobel A. Effects of selenium on morphological changes in Candida utilis ATCC 9950 yeast cells. Biol Trace Elem Res 2016; 169 (2): 387-393.

42. Ferlay J, Colombet M, Soerjomataram I, et al. Cancer incidence and mortality patterns in Europe: Estimates for 40 countries and 25 major cancers in 2018. Eur J Cancer 2018; 103: 356-387.

\section{AUTHORS' CONTRIBUTIONS}

KS prepared the concept of the paper, analysed data, interpreted data and wrote the draft manuscript. EC, JKS collected data, finally approved the publication and critically revised it. 